\title{
NARRATIVAS SOBRE A FORMAÇÃO DE PROFESSORES EM MATO GROSSO DO SUL COMO PATRIMONIO EDUCATIVO
}

\author{
Carla Regina Mariano da Silva \\ Universidade Federal de Mato Grosso do Sul \\ carla.silva@ufms.br \\ Katia Guerchi Gonzales \\ Universidade Anhanguera Uniderp \\ profkatiaguerchi@gmail.com
}

\begin{abstract}
RESUMO
Este artigo aborda as contribuições de narrativas produzidas em uma pesquisa que trabalha com a metodologia de pesquisa em História Oral para a escrita da História. A pesquisa tomada neste texto tinha como objetivo investigar a formação de professores de Matemática em Mato Grosso do Sul. A discussão que aqui se apresenta toma aspectos presentes nos textos narrados como disparadores para a discussão sobre a correlação das narrativas com o conceito de Patrimônio Educativo. As memórias registradas por meio da História Oral em narrativas, presentifica o valor sócio-histórico e cultural dos âmbitos escolares o que torna imprescindível sua preservação realizada por meio da sua fixação na escrita.
\end{abstract}

Palavras-chave: Patrimônio. História da Educação Matemática. Narrativa.

\section{NARRATIVES ON TEACHER TRAINING IN MATO GROSSO DO SUL AS EDUCATIONAL HERITAGE}

\begin{abstract}
This article approaches the contributions of narrative produced in researches that work with the methodology of research in Oral History for the writing of History. The researches taken in these texts, had as objective to investigate the formation of teachers of Mathematics in Mato Grosso do Sul. The present discussion takes aspects present in the texts narrated as triggers for the discussion about the correlation of the narratives with the concept of Patrimony Educational. The memories recorded through oral history in narratives, presentifica the socio-historical and cultural value of school environments which makes it imperative to preserve it by means of its fixation in writing.
\end{abstract}

Keywords: Heritage. History of Mathematics Education. Narrative.

\section{NARRATIVAS SOBRE LA FORMACIÓN DE PROFESORES EN MATO GRUESO DEL SUR COMO PATRIMONIO EDUCATIVO}

\section{RESUMEN}

Este artículo aborda las contribuciones de narrativas producidas en investigacion que trabaja con la metodología de investigación en Historia Oral para la escritura de la Historia. La investigacion tomada en esto texto, tenían como objetivo investigar la formación de profesores de Matemáticas en Mato Grosso do Sul. La discusión que aquí se presenta, toma aspectos presentes en los textos narrados como disparadores para la discusión sobre la correlación de las 
narrativas con el concepto de Patrimonio educativo. Las memorias registradas por medio de la Historia Oral en narrativas, presentifica el valor sociocultural y cultural de los ámbitos escolares lo que hace imprecindible su preservación realizada por medio de su fijación en la escritura.

Palabras clave: Patrimonio. Historia de la Educación Matemática. Narrativa.

\section{NARRATIVES SUR LA FORMATION DES ENSEIGNANTS À MATO GROSSO DO SUL COMME PATRIMOINE ÉDUCATIF}

\section{RÉSUMÉ}

Cet article aborde les contributions du récit produit dan le recherche qui travaillent avec la méthodologie de la recherche en histoire orale pour l'écriture de l'histoire. Le recherche menée dan ces texte avaient pour objectif d'étudier la formation des professeurs de mathématiques au Mato Grosso do Sul. La présente discussion prend en compte les aspects présents dans les textes narrés comme déclencheurs de la discussion sur la corrélation des récits avec le concept de patrimoine. Éducatif. Les souvenirs enregistrés à travers l'histoire orale dans les récits présentent la valeur socio-historique et culturelle des environnements scolaires, ce qui rend impératif de le préserver par sa fixation par écrit.

Mots-clés: Patrimoine. Histoire de l'enseignement des mathématiques. Narration.

\section{INTRODUÇÃO}

Este texto tem como objetivo explicitar as contribuições de sujeitos para a escrita de histórias sobre a formação de professores de Matemática em um estado do centro-oeste brasileiro. As discussões aqui presentes foram realizadas no âmbito da Educação Matemática, mais especificamente na área de História da Educação Matemática, que, segundo Miguel (2014), é um campo que toma como objeto de investigação "todas as práticas educativas mobilizadoras de cultura matemática em quaisquer contextos de atividade humana, dentre eles, sobretudo, os contextos educativos escolares” (MIGUEL, 2014, p. 31). Inserido nesse campo e tendo como objetivo estudar a formação de professores de Matemática via cursos institucionais, no Sul de Mato Grosso Uno, a tese de Silva (2015) é composta por dez narrativas produzidas a partir da metodologia de História Oral.

A produção de narrativas a partir de entrevistas utilizando como metodologia a História Oral tem sido objeto de estudos no grupo GHOEM - Grupo de História Oral e Educação Matemática, desde sua criação em 2002, e durante esses quase 16 anos, inúmeros foram os trabalhos produzidos sob essa metodologia. A História Oral tem sido concebida dentro do grupo, do qual fazemos parte, como uma metodologia de pesquisa no sentido amplo, uma vez que entendemos metodologia tal qual Garnica (2015, p. 38), "não apenas como um mero 
conjunto de procedimentos, mas como um complexo que exige também a fundamentação desses procedimentos".

Historicamente, a História Oral já foi utilizada como uma metodologia de investigação social, sendo um instrumento de luta política, ao dar voz aos sujeitos que estão à margem da sociedade, em lugares ocultados e silenciados pela história de grandes nomes. Esse tom quase benevolente tem sido substituído por uma ideia de História Oral como uma postura metodológica inclusiva (CARVALHO; RIBEIRO, 2014), na qual os sujeitos com suas experiências e subjetividades participam e são atores principais no processo de produzir conhecimento.

Sendo uma metodologia de pesquisa, há regulações no trabalho com fontes orais que vêm sendo construídas e reconstruídas a cada estudo realizado pelo grupo. Com inspirações no que Meihy e Holanda (2007) discutem em seu livro História Oral: como fazer, como pensar, a produção de uma entrevista tem sido realizada a partir de alguns procedimentos recorrentes. Estabelecido um tema de pesquisa, vai-se a busca de personagens que possam contribuir na produção da história que se quer contar. Com um roteiro pré-determinado em mãos, a entrevista é realizada e gravada em áudio ou vídeo e depois transcrita respeitando e registrando tal qual foi dito. Na transcrição se busca registrar na escrita todos os detalhes da entrevista realizada, incluindo aspectos comuns a oralidade como a repetição de palavras, pausas, entre outros aspectos. Em um segundo momento, o texto transcrito é trabalhado de modo que se construa um texto mais próximo da linguagem escrita, a esse texto damos o nome de textualização. Feito isso, o material é enviado ao entrevistado e ele, caso queira, pode sugerir correções sobre o texto ou assentir a sua publicação. Esse movimento entre entrevistado e entrevistador pode ter, inclusive, várias idas e vindas até que se estabeleça um texto em comum acordo. O último momento dessa fase de produção de fontes é a assinatura da carta de cessão ou termo de autorização de uso, no qual o entrevistado permite que o texto seja utilizado como fonte de pesquisa.

A eleição dos entrevistados é realizada a partir do critério de rede, no qual o próprio entrevistado seja na sua narrativa, ou em falas posteriores, nos indica um possível novo depoente. Apesar desses procedimentos terem uma certa constância nas pesquisas realizadas pelo grupo, a cada novo estudo há uma análise criteriosa dos procedimentos metodológicos utilizados durante toda a pesquisa. Essa análise é feita apontando sucessos e fracassos vividos durante a pesquisa, e visa promover reflexões em pesquisas futuras. O próprio entendimento da textualização como uma narrativa produzida em momento de entrevista, tem sido tomado como importante há poucos anos e nos parece abrir a discussão sobre as fontes produzidas. Entender 
as fontes orais como narrativas orais, possibilita ao pesquisador que trabalha com História Oral, o uso de outras narrativas, sejam elas de qualquer natureza.

Especificamente para as discussões aqui presentes, entendemos que as contribuições dos sujeitos, via narrativas produzidas, trazem novos aspectos ao debate sobre a história das instituições, e, sendo a principal característica do texto narrado a subjetividade, ampliam o conceito de patrimônio educativo.

A partir do momento em que a escola passa a ser considerada um lugar de memória (NORA, 1993) cria-se a necessidade de salvaguarda de aspectos físicos e materiais do ambiente escolar. Ou seja, a escola passa a ser vista como um patrimônio digno a ser preservado, um patrimônio educativo. Prédios escolares do início do século são tombados, e os arquivos escolares abandonados pelo tempo, se constituem como arquivos desejáveis a qualquer pesquisador da História da Educação. O que propomos aqui é a ampliação desses conceitos ao considerarmos as narrativas orais como parte do patrimônio educativo e, portanto, dignas de serem registradas. A subjetividade presente na narrativa parece trazer para as pesquisas em História da Educação Matemática, que delas utilizam, um outro modo de entender o conceito de patrimônio educativo, e é isso que nos propomos discutir neste texto.

Em nossos estudos, assim como nos demais realizados pelos grupos ${ }^{1}$ que fazemos parte, a entrevista é uma produção realizada pelo entrevistado e pelo entrevistador que, marcada por traços de subjetividade, possibilita a criação de uma fonte em sintonia com o objetivo da investigação. Se nosso interesse é pesquisar o movimento de criação e implementação de cursos que formaram professores, em determinada região, a fala daqueles que participaram desses momentos pode nos trazer inúmeras contribuições, diferentes perspectivas e múltiplas leituras de mundo.

As narrativas produzidas utilizando a metodologia de história oral “[...] possibilitam que tenhamos acesso à cultura matemática escolar de um modo diferente daquele que nos propiciam a legislação, as prescrições curriculares, os livros didáticos e os diversos documentos dos arquivos escolares" (GOMES, 2012, p. 133). Salientamos que dizer que são diferentes não significa estabelecer uma hierarquia entre as fontes, ao contrário, é entender que a multiplicidade abre um leque de possibilidades e visões de mundo.

A realidade é produzida a partir daquilo que o sujeito vivenciou, em um acréscimo narrativo, e por isso, interna ao sujeito (BRUNER, 1991). Nesse sentido, entendemos que as

\footnotetext{
${ }^{1}$ GHOEM e HEMEP - História da Educação Matemática em Pesquisa - UFMS - Campo Grande-MS.
} 
pesquisas que utilizam a metodologia de história oral buscam ampliar e democratizar as vozes participantes da produção de conhecimento histórico. Não há, no entanto, a preocupação de se promover um confronto entre as fontes orais para que desse, em cotejamento, surja uma verdade mais clara, geral, profunda ou definitiva. Não entendemos a fala do entrevistado como "a verdade" dos fatos, mas sim como uma maneira de ampliarmos as perspectivas considerando uma outra produção. A subjetividade da entrevista - à qual, no passado, foi negada a prerrogativa de cientificidade -, exatamente por marcar o registro com a não neutralidade, é o que a torna tão importante na produção das histórias.

Desse modo, estamos aqui entendendo que o uso de narrativas na escrita da história tem potencialidades para ampliar aquele conceito de patrimônio educativo como os objetos que compõem a cultura material da escola. Em outras palavras, propomos que passemos a entender não somente os aspectos materiais, como também as memórias daqueles que participaram do processo educativo como um patrimônio, e que como tal, deve ser preservado ao fixarmos as narrativas na escrita.

\section{O PATRIMÔNIO EDUCATIVO}

Nas últimas décadas, a Memória, como objeto de estudo, tem despertado o interesse entre, neurologistas, psicólogos, psiquiatras, antropólogos, sociólogos e historiadores. E quando trabalhada na historiografia, quase sempre torna fundamental a explicitação dos limites, das influências e das interdependências entre memória e história. Pierre Nora, faz isso muito bem:

Memória, história: longe de serem sinônimos, tomamos consciência que tudo opõe
uma à outra. A memória é a vida, sempre carregada por grupos vivos e, nesse sentido,
ela está em permanente evolução, aberta à dialética da lembrança e do esquecimento,
inconsciente de suas deformações sucessivas, vulnerável a todos os usos e
manipulações, suscetível (sic) de longas latências e de repentinas revitalizações. A
história é a reconstrução sempre problemática e incompleta do que não existe mais. A
memória é um fenômeno sempre atual, um elo vivido no eterno presente; a história,
uma representação do passado, Porque é afetiva e mágica, a memória não se acomoda
a detalhes que a confortam; ela se alimenta de lembranças vagas, telescópicas, globais
ou flutuantes, particulares ou simbólicas, sensível a todas as transferências, cenas,
censura ou projeções. A história, porque operação intelectual e laicizante, demanda
análise e discurso crítico. A memória instala a lembrança no sagrado, a história a
liberta, e a torna sempre prosaica. A memória emerge de um grupo que ela une, o que
quer dizer, como Halbwachs o fez, que há tantas memórias quantos grupos existem;
que ela é, por natureza, múltipla e desacelerada, coletiva, plural e individualizada. A
história, ao contrário, pertence a todos e a ninguém, o que lhe dá uma vocação para o
universal. A memória se enraíza no concreto, no espaço, no gesto, na imagem, no
objeto. A história só se liga às continuidades temporais, às evoluções e às relações das
coisas. A memória é um absoluto e a história só conhece o relativo. (NORA, 1993, p.
9)

Rev. Iberoam. Patrim. Histórico-Educativo, Campinas (SP), v. 5, p. 1-20, e019004, 2019 
Nessa perspectiva, a partir das diferenças salientadas por Nora (1993), podemos dizer que a fronteira entre História e Memória é tênue e que ambas são modos distintos de representação do passado, contudo, nenhum desses modos é superior ao outro. Damos destaque, no entanto, no que essencialmente os difere, pois enquanto a História opera com procedimentos científicos, na busca por evidências, na crítica das fontes e na busca da verdade; a memória é leal ao passado que oferece o testemunho. Assim, de modo resumido, enfatizamos que a memória pode ser vista como a presentificação da vida e mantêm-se no tempo, renovando-se.

De acordo com Viñao (2011), abordar a memória como tema de pesquisa, por si só, causa grandes debates na academia. Ainda, mais fundamental, para aqueles que trabalham com a história da Educação, é a necessidade de evidenciar as relações e interações entre memória e patrimônio educativo. Essas aproximações são feitas de uma forma bem didática por Viñao (2011) que, incialmente, discute o conceito de patrimônio de modo ainda embrionário, baseando-se em seus diferentes significados apresentados no dicionário da Royal Academy. Assim, explica-nos que:

[...] o patrimônio é algo valioso que é herdado ou construído; ao mesmo tempo, é algo que é considerado adequado no sentido de que é parte daquilo de que é propriedade. Em outras palavras, não é estático, dada uma vez por todas e imutável, precisamente porque exige consciência ou sentimento que nos pertence, que é de alguma forma valioso e que, portanto, precisa ser preservado e protegido. (VIÑAO, 2011, p. 34, tradução nossa).

Por esse prisma, o patrimônio é entendido como herança, não individual, mas coletiva, no qual há consciência de todos os integrantes de determinado grupo social - com base em laços culturais, linguísticos, religiosos ou ideológicos - que fazem parte dele. Desse modo, algo se torna herança quando o grupo considera que esse algo deva ser conservado, preservado. Nas palavras de Viñao (2011, p. 34, tradução nossa), a herança “torna-se um lugar de memória e no qual deposita-se a memória, em algo para lembrar e nos fazer lembrar".

A memória, de determinado grupo, constitui uma identidade social, quando reconhecida como narrativa do passado. Para autores como Ricardo de Aguiar Pacheco (2010), a memória não só salienta elementos de um passado, mas explicita potencialidades de um futuro que se busca constituir. Nessa vertente, ao selecionar elementos sociais como patrimônio para determinada comunidade, além de significativos para aquele grupo social, dizem muito a respeito dos integrantes do grupo, reforçando quem são em relação ao outro. Afirmamos, nesse contexto, que os elementos que passam a constituir o patrimônio histórico das comunidades são aqueles reconhecidos pelos integrantes do grupo social, que por sua vez, passam a incorporálos à sua experiência. 
Visto, então, como herança, o patrimônio não é algo dado, mas sim um processo infinito de construção e reconstrução, o que torna historicamente variável a noção de patrimônio histórico ou cultural (VIÑ̃̃O, 2011).

Com relação às ideias propostas por Viñao (2011), há de se observar, que a história é a ligação entre memória e patrimônio e que a educação institucional é "aquela atividade ou tarefa que as sociedades vêm configurando ao longo de vários séculos para realizar, de maneira sistemática e formalizada, essa transmissão" (VIÑAO, 2011, p. 35, tradução nossa).

A dificuldade em diferir a história e memória é de certo modo aceitável, dadas as suas interdependências e influências. Um aspecto, no entanto, comum a ambas é seletividade, uma vez que se preserva uma restrita parte do que aconteceu. A história, no entanto, segundo as ideias de Viñao(2011), está a serviço da memória, uma vez que esta última tem o poder de comemorar o passado e recriá-lo atribuindo sentido ao que se passou. Viñao, explica-nos que "a história vive, em parte, graças ao ritmo desse fenômeno ou aspecto da memória social que são as comemorações" (VIÑAO, 2011, p. 36, tradução nossa).

Pacheco (2010) reforça que a ação do historiador no campo do patrimônio não deve se limitar a sistematizar um discurso coerente a respeito do passado - entendido por nós, em nossos trabalhos, como narrativa -, mas sim, de articular essa narrativa produzida pelo historiador e pelo sujeito narrador, às várias outras visões que os integrantes da comunidade que se busca investigar, desejam legitimar sobre o seu passado, ou seja, sobre a memória que desejam preservar.

Relacionando essas ideias com o campo da História da Educação tem-se, segundo Mogarro (2013), que a ideia de patrimônio educativo,

[...] a sua história e sua memória comungam das propostas políticas de renovação social e são parte integrante de um movimento que atribui grande significado aos discursos dos actores educativos e com os processos de ensino e aprendizagem que ocorrem em tempo real nas escolas e nas salas de aula e em que eles adquirem o seu conhecimento experiencial. (MOGARRO, 2013, p. 71).

Fazem parte desse processo os objetos culturais materiais e por meio deles, juntamente com as narrativas por nós produzidas, é que investigamos os sistemas educativos.

O património educativo inclui uma grande diversidade de elementos, como: a arquitectura escolar, com o edifício das instituições e o espaço envolvente, com as suas funções e uma forte relação com a vida local; os equipamentos, como carteiras, quadros, armários, etc.; os objectos de uso quotidiano; os materiais didácticos, nomeadamente os instrumentos científico-didácticos para o ensino das disciplinas como biologia ou física, os quadros parietais, as caixas métricas, os ábacos; os meios audiovisuais; os trabalhos de alunos, os cadernos escolares e muitos outros. É necessário também estabelecer a correlação entre os objectos e documentos de outro tipo com eles articulados, tais como as fotografias, as imagens e os documentos em

Rev. Iberoam. Patrim. Histórico-Educativo, Campinas (SP), v. 5, p. 1-20, e019004, 2019 
suporte de papel (catálogos de casas editoras, material bibliográfico, manuais de ensino, que muitas vezes explicam a utilização e funcionamento do material didáctico, documentos de arquivo correlacionados com os objectos, como requisições, notas de compra, etc.). (MOGARRO, 2013, p. 93).

Mogarro (2013) menciona a ideia de que o movimento de preservação e valorização do patrimônio da educação tem ganhado relevância internacionalmente nos campos científicos da educação e da história. Destaca assim, pesquisas neste viés em países como a França, Espanha, Holanda, Bélgica e Grã-Bretanha. Essa perspectiva de pesquisa, segundo a autora, tem constituído uma área de fronteira singular entre o campo da educação e da história, que pode ser observada, segundo suas pesquisas, a partir de 2010 com a consolidação de linhas de pesquisa sobre a cultura escolar ${ }^{2} \mathrm{e}$ o patrimônio educativo, e também, com as publicações coletivas que reforçam a intensificação do diálogo entre os investigadores.

Neste viés, Mogarro (2013) apresenta um projeto de pesquisa denominado Educação e Patrimônio Cultural: escolas objetos e práticas (2010-2013) sobre o patrimônio cultural da educação em Portugal. Foca assim, no patrimônio educativo, explicitando a metodologia, análise e divulgação dos resultados de um estudo que buscou identificar a situação de Portugal à época, relacionando a realidade de outras comunidades científicas de países europeus. Buscou, então, estudar, recuperar e divulgar o patrimônio educativo português, colaborando assim, para a sua preservação.

Em face a esse tema, essa autora ainda discorre sobre as dimensões múltiplas que há no patrimônio educativo, realçando que é imprescindível conceber materiais em suporte de papel pois ao estudar a história das disciplinas escolares e os processos de ensino e aprendizagem, cotejamos a literatura articulada com o tema, aos documentos de arquivo, e aos materiais didáticos. Mogarro (2013) faz essa observação, principalmente, ao considerar os materiais didáticos e as práticas pedagógicas como patrimônio educativo, reforçando a necessidade de investigar os autores dos materiais que os elaboraram ou adequaram, e também

\footnotetext{
${ }^{2}$ De imediato, devemos ressaltar o que entendemos por cultura. Sendo assim, a cultura, antes de tudo, é uma produção social, que se traduz por produtos, objetos concretos ou abstratos, que são criados para resolver um determinado problema da sociedade e preservados através das gerações, porém, apesar disso, não são estáticos, modificam-se com o passar do tempo, aprimorando-se. O conceito de cultura escolar, no sentido proposto por Dominique Julia (2001), é explicado da seguinte maneira: “[...] cultura escolar é descrita como um conjunto de normas que definem conhecimentos a ensinar e condutas a inculcar, e um conjunto de práticas que permitem a transmissão desses conhecimentos e a incorporação desses comportamentos; normas e práticas coordenadas que podem variar segundo as épocas" (JULIA, 2001, p. 10). O autor salienta que a cultura escolar não pode ser analisada desprovida das relações que lhe são naturais, ou seja, é primordial, para compreendê-la, verificar as possíveis relações existentes ao conjunto de cultura de um determinado período e local. Para Chervel (1990), a cultura escolar busca valorizar os procedimentos e os conhecimentos que são característicos do contexto escolar de modo diferente daqueles que são produzidos fora da instituição escolar e são levados a ela.
} 
as editoras que os produzem e publicam. Além disso, evidencia a relevância de articular tais materiais aos contextos educativos que eles foram produzidos, propagados e apropriados. Conferindo a importância de investigar os alunos e as características das suas aprendizagens, tomando esses autores educativos como elementos essenciais nos contextos institucionais de ensino.

Em análise convergente, Souza (2013) discute os desafios para a preservação do patrimônio escolar no Brasil. Propriamente no que tange tal discussão significa e amplia a concepção de patrimônio cultural e escolar, e também, discute a noção da cultura material e imaterial $^{3}$, destacando que:

[...] estudos sobre a cultura material escolar têm posto em discussão os sentidos da relação entre objetos, sujeitos e rotinas escolares, descortinando dimensões pouco exploradas do universo escolar, salientando como o olhar para as coisas comuns pode ser relevante para o conhecimento e a interpretação histórica da educação. (SOUZA, 2013, p. 205).

Neste sentido, a autora explica-nos que pesquisadores e grupos de pesquisa vêm se debruçando e investindo na organização, recuperação e conservação de fontes, arquivos e bibliotecas. Contudo, explica-nos que ao utilizarmos o termo patrimônios escolares, não estamos nos referindo apenas aos bens materiais, mas também aos imateriais. Visto dessa forma, podemos dizer que a análise de processos, práticas e materialidades educativas, busca preservar além de acervos documentais, prédios, materiais didáticos, também, os modos de fazer e praticar o ensino, explorando a diversidade dos bens tangíveis e intangíveis.

Tal aspecto, implica em considerar a memória, levando em conta "os princípios constitucionais culturais, isto é, o pluralismo cultural, a participação popular, a atuação estatal como suporte logístico, o respeito à memória coletiva e a universalidade" (SOUZA, 2013, p. 213).

Consideramos então, que as memórias registradas por meio da História Oral em narrativas, presentifica o valor sócio-histórico e cultural dos âmbitos escolares. Deve assim, o historiador da educação, conservar e divulgar esse patrimônio educativo ${ }^{4}$ gerado pela

\footnotetext{
${ }^{3}$ É importante ressaltar que a cultura material está relacionada com o significado que determinados objetos possuem para um dado grupo. Sendo estes produzidos em contextos e períodos específicos da história de um lugar. Desse modo, pode-se dizer que a cultura material diz respeito a quase toda produção humana. Já a cultura imaterial é uma manifestação de elementos que vão além do material, de objetos, são inerentes de práticas, costumes e hábitos. Sua transmissão acontecer muitas vezes pela tradição.

${ }^{4}$ A título de exemplo podemos citar o trabalho de Souza (2011) que teve como objetivo principal construir uma versão histórica sobre o ensino de matemática no Grupo Escolar Eliazar Braga no período de 1920 a 1975 na cidade de Pederneiras, interior do estado de São Paulo. Para isso, um grupo de pesquisadores se colocaram em movimento para preservar e organizar o arquivo do grupo escolar em foco, conservando assim, esse patrimônio educativo para a comunidade escolar. Além disso, a publicação da tese e de artigos sobre esse arquivo escolar
} 
comunidade escolar, que traz em si a herança de um grupo social que produz e reelabora o contexto educativo em profunda cumplicidade com a história e a memória desse patrimônio que buscamos preservar e reinventar constantemente.

Ao entender, portanto, as narrativas produzidas pelos sujeitos como um patrimônio educativo, que como tal, merece ser cuidado e preservado, resta-nos discutir o que entendemos por narrativas e como essas foram importantes para a construção de histórias sobre os cursos institucionais de formação de professores em Mato Grosso do Sul, centro-oeste brasileiro.

\section{NARRATIVAS: RECONHECENDO-AS COMO HERANÇAS}

Bolívar, Domingo e Fernández (2001, p. 20) entendem as narrativas como "uma particular reconstrução da experiência a partir da qual, mediante um processo reflexivo, é possível atribuir significado ao vivido". A Narrativa, nesse sentido, pode ser vista como a mediação entre o tempo vivido e a significação da ação e, desse modo, toda ação só ganha sentido no entrelaçamento dos significados atribuídos contextualmente. A experiência tornase, então, elemento fundamental, se não o elemento principal de uma narrativa: uma narrativa é relato e registro de experiências.

Bruner (2014), em seu livro: Fabricando Histórias: direito, literatura e vida, discute a produção de uma narrativa como um equilíbrio entre aspectos internos e externos o sujeito. Como aspecto interno, a memória é o combustível a partir do qual narramos, no entanto, não narramos qualquer coisa que nos vem a mente uma vez que o nosso compromisso com o outro nos impede de narrarmos qualquer coisa. Ou ainda, temos a autonomia para narrar, mas narramos o que achamos que o outro quer ouvir de nós. Esse segundo, aspecto considerado por Bruner (2014) como externo, está intimamente ligado a quem se narra, ou ainda, ao ouvinte ou leitor que constituímos em nossa mente ao narrar.

Entendemos ainda as narrativas, assim como Vidal (2009) compreende as fotografias em seus estudos, ou seja, as narrativas não servem apenas para ilustrar, elas são o nosso objeto

proporcionaram a divulgação de heranças educacionais até então desconhecidas ou até mesmo esquecidas. Outro exemplo de ampla divulgação e conservação de patrimônio educativo é o HEMERA, um sistematizador de textualizações criado pelo Grupo de História Oral e Educação Matemática - Ghoem e desenvolvido como parte do trabalho de doutorado de Fábio Donzeti de Oliveira em 2013, sob o título Hemera: sistematizar textualizações, possibilitar narrativas. A finalidade desse programa é produzir, por meio das narrativas criadas pelos membros do Ghoem, outras possíveis narrativas sobre os mais diversos temas. Desse modo há ampla divulgação e conservação do patrimônio educativo. 
de estudo; e se assim as entendemos, será fundamentalmente a partir delas, e por meio delas, constituirmos compreensões sobre determinado tema de estudo.

Um dos primeiros textos que nos fez pensar essa forma de trabalhar foi o Sinfonia $n .^{o}$ 5 em Dó menor, de Carlos Roberto Vianna, publicado em 2016 e discutido em uma das reuniões do Ghoem em Bauru-SP. Nesse artigo, o autor trata da Educação Matemática sem dizer explicitamente sobre o assunto. Discorre sobre algumas de suas experiências, retratando-as e (re)interpretando-as, segundo as suas perspectivas, ideologias e formação. Faz, assim, uma observação:

Peço então atenção para a proposta: não indaguemos sobre "a matemática" quando eu estiver falando sobre música, pois quando falo de música estou ao menos pensando em matemática... e não indaguemos sobre a "pintura" quando eu estiver falando de filosofia, pois se falar de filosofia estarei pensando em uma pintura, mas não falarei sobre filosofia em momento algum, ainda que sempre que fale sobre educação matemática esteja pensando em filosofia... e assim por diante. (VIANNA, 2016, p. 47).

$\mathrm{O}$ autor advoga em seu artigo que as referências podem ser bem mais do que aquelas previstas nas normas da Associação Brasileira de Normas Técnicas (ABNT) e, nos apresenta seu exercício ao escrever o texto que, para ele, foi um mergulho no campo das relações, deixando fluir as referências em livres associações. Em seus encadeamentos, para argumentar sobre o seu modo de referenciar, remete, em uma das passagens, a Feyerabend, contrariando-o quando ele ressalta que os cientistas acabam deixando de lado "coisas como a sua religião, sua metafísica, o seu senso de humor e mesmo a sua imaginação e linguagem”. Observa, assim, que "a memória e as associações de ideias podem nos levar longe" (VIANNA, 2016, p. 55) declarando, que, para ele, "as relações da vida e da matemática se tornam indissolúveis" (VIANNA, 2016, p. 56). E essa é a proposta no seu texto, isto é, apresentar as possíveis relações entre as artes, as coisas do mundo e as matemáticas, explicando, ainda, que elas não decorrem de aplicações, elas constituem umas às outras, e tudo isso a partir da experiência do pesquisador.

Isso nos conduz à afirmativa de Albuquerque Júnior (2007, p. 87) de que a História "deve tratar das descontinuidades que nos constituíram, da multiplicidade de experiências disparadas e sem roteiro prévio que tornou possível ser como somos". Essas ideias nos fazem pensar sobre as narrativas, pois quando o sujeito narra suas experiências - mesmo que não diga explicitamente o que buscamos entender ou não responda diretamente nossas questões -, ele faz relações com outras coisas que viveu que, à primeira vista, podem não estar relacionadas com o assunto, mas que, na verdade, são fundamentais e importantes, afinal são encadeamentos que o constituem e que permitem que ele fale sobre determinado tema. 
Nessa perspectiva, como para Ricoeur (1997, p. 425), para nós, a vida é “um tecido de histórias narradas", em que o trabalho hermenêutico - ou seja, o processo de reinterpretar a experiência - possibilita a refiguração da história de uma vida. Destarte, é por meio da imaginação que há possibilidade do homem refazer a compreensão de si mesmo.

O combustível da elaboração de uma narrativa é a memória da experiência vivida, e nesse sentido, os colaboradores, em uma pesquisa que utiliza a metodologia de história oral, constituem-se, refiguram-se por meio das próprias narrativas. Constituem-se como leitores e também como escritores de suas próprias vidas, já que "a história de uma vida não cessa de ser refigurada por todas as histórias verídicas ou fictícias que um sujeito conta de si mesmo" (RICOEUR, 1997, p. 425).

Não buscamos, nos relatos, nas entrevistas, acesso as experiências vivenciadas pelos nossos colaboradores: o que procuramos é uma versão do que ocorreu de acordo com a perspectiva de quem vivenciou algo, de quem viveu certas coisas. Para nós, as narrativas ajudam a compreender a experiência e o objeto experienciado, permitindo atribuir sentido a essas variadas experiências, que são, a todo momento, ressignificadas pelos nossos colaboradores quando nos relatam algo.

As narrativas são formas de estruturar as experiências como relatos (BENJAMIN, 1994) e, portanto, o que analisamos em uma pesquisa, que tem narrativas como fontes, não é a experiência do outro, mas o relato dessa experiência. Ao analisar as narrativas, podemos dizer que, de acordo com Larrosa (2014), um pesquisador sempre produz um sentido; busca que as experiências com as quais trabalha signifiquem algo. Tenta, por meio do relato das experiências, algo que se compreenda, mesmo que a experiência singular tenha sempre algo de incompreensível; algo que somente a traição e a violência podem converter em outra coisa. Por isso, como pesquisadores, devemos ter cuidado para não falsificar as experiências ${ }^{5}$ de nossos colaboradores, tentando fazê-las significativas (LARROSA, 2014), uma vez que nós, os pesquisadores que trabalhamos com as ideias e com as palavras; somos como o jornalista de Sem destino ${ }^{6}$, já que a nós é confiada a missão de estabelecer uma relação entre as palavras e as coisas, entre a experiência e o sentido e, por vezes, falamos em nome dos outros para ter algo

\footnotetext{
${ }^{5} \mathrm{O}$ pesquisador que trabalha com a história e lança mão das narrativas em seus estudos, tem que ter cautela para não forçar dar sentido a fala do narrador, impondo um significado que a narrativa não representa.

${ }^{6}$ Para problematizar a relação entre experiência, subjetividade e relato, Larrosa (2002) vale-se de alguns escritos de Imre Kertész - húngaro que ganhou o Nobel de Literatura em 2002 - autor de romances autobiográficos sobre experiências nos campos de concentração nazistas e na ditadura comunista de seu país. Dentre as obras analisadas está o livro Sem destino.
} 
a dizer, convertemos o relato das experiências e as subjetividades dos outros em experiências e subjetividades compreensíveis.

É preciso, neste sentido, reafirmar que a ideia não é, a partir de uma narrativa de um colaborador ou de um conjunto das narrativas, tecer generalizações, transcendendo a subjetividade dos nossos narradores. Não devemos cristalizar uma determinada forma-homem e tornar unidade o que é múltiplo (FERNANDES, 2014). Tentamos, no entanto, como pesquisadores, compreender a realidade que nos cerca, atentando e respeitando os modos "pelos quais o outro atribui significado às suas próprias experiências" (GARNICA, 2007, p. 59). Fernandes (2014, p. 898-899) também nos lembra que “Orvalho não é orvalho sozinho: ele só é vida no conjunto de relações que estabelece. Orvalho não existe, o que existem são as circunstâncias que o constituem orvalho." De tal modo, o sujeito só é sujeito nas relações que desenvolve, que o afetam, que o tocam e que o tornam o que é.

É oportuno reiterar que, para “fazer história não é necessário se afastar do mundo, das coisas, das pessoas, mas estar tão próximo delas que já não saibamos quando começa o eu e o outro, o eu e eles" (ALBUQUERQUE JÚNIOR, 2007, p. 89). Só com esse pensamento, nós, educadores matemáticos que trabalhamos com pesquisas numa abordagem historiográfica, conseguimos analisar as narrativas - que nada mais são que um emaranhado já composto de significação, onde não sabemos em que parte inicia ou termina o pesquisador e o colaborador e atribuir significados aos relatos.

\section{A IMPORTÂNCIA DAS NARRATIVAS PARA A ELABORAÇÃO DE HISTÓRIAS}

Buscamos exemplificar agora o que temos argumentado durante o texto, ou seja, a importância das narrativas orais para a escrita da história sobre as instituições escolares, a fim de concluirmos que essas também devem ser consideradas partes do patrimônio educativo e, portanto, preservadas.

Tendo, no entanto, como matéria-prima, a memória, a elaboração de uma narrativa é carregada de subjetividades, ou como Bruner (2014) nos ensina, é composta por aspectos internos e externos ao sujeito que narra. Não importa a distância temporal entre a elaboração de uma narrativa produzida e a experiência, a primeira sempre será uma elaboração intencional do vivido. O acesso ao acontecimento, em seu sentido literal, nos é negado, qualquer que seja qual fonte utilizada. Na pesquisa de Silva (2015) que investigou a criação de cursos de Ciências e Matemática no estado de Mato Grosso do Sul, temos narrativas que nos ajudam a explicitar 
as contribuições dessas para a escrita da história. Ainda que tendo utilizado outras fontes, as narrativas ocuparam papel central na trama produzida.

Na entrevista de Patusco em Silva (2015) temos um exemplo disso.

\begin{abstract}
Na década de 1980 aqui houve um "rebu" tremendo, porque o Gilberto Luiz Alves tentou acabar com os cursos de Administração e Contábeis. Não sei por que, acho que era política. A política aqui era muito forte, muito violenta[...] Enfim, a Universidade acabou se tornando um ambiente de guerra. Você queria saber como era não é? Chegou um ambiente de guerra entre os dois (Gilberto Luiz Alves e Salomão Baruki), de guerra mesmo, o pessoal quase partindo para a violência. (Silva, 2015, p. 412 e 414).
\end{abstract}

Aspectos de uma briga política entre dois partidos que influenciavam diretamente a abertura e fechamento de cursos em Corumbá-MS, na década de 1980, são discutidos explicitamente durante a narrativa de Patusco. Segundo ele, nada era dito abertamente, mas havia os professores que eram do time do Salomão e aqueles do time do Gilberto. Essa dinâmica da produção de significados, esse movimento contínuo de produzir histórias, possibilitado pelas entrevistas, permite que em um momento surjam elementos que em outro não poderiam surgir. Utilizando a noção de Regime de Historicidade, discutida por Garnica, Fernandes e Silva (2011), com inspirações em Hartog, dizemos que a história é produzida/fixada a partir do que se pode contar em determinada época. Em outros momentos, outras coisas poderiam ser ditas e fixadas.

Um outro aspecto que evidencia as contribuições da singularidade de uma narrativa para a pesquisa histórica, é o modo como a criação e manutenção de cursos para formação de professores foi narrada, tanto em Universidades Públicas como Privadas. Dentre os cursos para formar professores estudados em Silva (2015), três deles foram oferecidos por instituições públicas de ensino (a atual Universidade Federal de Mato Grosso do Sul - UFMS) e um deles pela instituição confessional (a atual Universidade Católica Dom Bosco - UCDB). Aspectos de uma narrativa presente em Silva (2015), nos indicam como era a dinâmica de criação e fechamento de cursos em uma instituição particular:

[...] Fechar uma licenciatura é... está funcionando com ingresso de 20 alunos, mas está funcionando porque a instituição tem um carinho especial pelas Licenciaturas devido a sua própria missão institucional, que é cuidar do jovem. Então, a formação do professor é importante. As Licenciaturas são subsidiadas aqui nessa instituição e mesmo assim não conseguimos manter Matemática. (SILVA, 2015, p. 18)

A missão salesiana de formar professores e o fato das licenciaturas serem subsidiadas na instituição é um dos itens ressaltados pela entrevista. No entanto, as diversas mudanças que 
tiveram que ser feitas no decorrer dos anos, visando aumentar a demanda dos cursos que formavam professores de Matemática mostram um outro lado dessa dinâmica.

Quando, no ano de 92, viemos para esse Campus, criamos e transformamos a Matemática numa Matemática chamada "Matemática Aplicada e Computacional" (depois lhe passo todas as datas). Com qual objetivo? Para ver se a gente salvava o curso de Matemática na instituição, porque ele era muito pequeno e, é claro, uma instituição privada não se mantém com um curso de quatro ou cinco alunos. (SILVA, 2015, p. 14).

O curso foi criado como Ciências, com duração de três anos, e algum tempo depois as habilitações em Matemática e Biologia passaram a ser oferecidas. Havia, portanto, uma entrada considerável de alunos, mas no ato da escolha da habilitação, a maioria preferia a área biológica e poucos eram os que seguiam para a Matemática. Isso resultava em um curso, em seus anos finais, com poucos alunos o que, aparentemente, não era interessante para a instituição. A mudança seguinte transformou o curso em Matemática Computacional visando aumentar a demanda, o que realmente aconteceu, por um certo período de tempo. O que podemos perceber, no entanto, durante a narrativa produzida em Silva (2015) é que, aos poucos, a missão de formar professores foi sendo deixada de lado pela sobrevivência de um curso e de um grupo de professores que ali trabalhavam. Ainda que afirmando a importância da formação de professores para a instituição, a ênfase dada aos empregos em concursos públicos ou em outras áreas e o orgulho pelos caminhos seguidos por seus alunos que, mesmo tendo feito um curso de licenciatura, foram trabalhar em áreas diversas, parece acenar para um fato: o desprestígio da carreira docente.

Um outro aspecto narrado em Silva (2015) nos possibilita falar sobre diferenças e semelhanças na abertura e extinção de cursos em instituições públicas e privadas. Três foram os cursos estudados oferecidos pela UFMS, dois deles em cidades pelo interior do estado de Mato Grosso do Sul e um deles na capital, Campo Grande. Um dos primeiros aspectos que intrigaram Silva (2015) quando do primeiro levantamento feito, foi a distância temporal entre a criação desses cursos. Algo em torno de 10 anos. As narrativas possibilitaram que um outro olhar fosse lançado para essas datas. Um primeiro aspecto foi o fato do curso criado na capital ser de Licenciatura em Matemática, em oposição aos cursos de Ciências criados pelo interior do estado e a resistência dos professores que trabalhavam na capital em criar um curso de Ciências. Uma outra questão, está na diversidade de cursos criados na capital em oposição à aqueles criados no interior do estado. Em ambos os casos, o desprestígio dos cursos de Licenciatura parece estar presente. Na capital, cursos de Engenharia, Farmácia, Odontologia e Medicina foram criados na década de 1960, na atual capital, Campo Grande, enquanto as 
licenciaturas poderiam ser oferecidas nos campus do interior, pois exigiam menos estrutura. Além disso, as cidades do interior eram menos atrativas a profissionais já formados que poderiam atuar como professores nas mais diversas áreas (Campo Grande, apesar de sua criação recente, atraía profissionais de diferentes campos, em um processo migratório intenso já nas décadas de 1950 e 1960). Além desses profissionais, os próprios alunos do curso de Engenharia da UFMS de Campo Grande atuavam como professores do Ensino de $1^{\circ}$ e $2^{\circ}$ graus.

Veja que esse outro aspecto presente nas narrativas em Silva (2015), muito nos diz sobre a dinâmica da criação de cursos nas instituições públicas. Em locais em que a estrutura era menor, o curso eleito era o de licenciatura, já na capital, outros cursos poderiam ser criados. Esse aspecto singular quando olhamos para as instituições de ensino superior públicas, parece caminhar para um ponto no qual se ofereça algum tipo de formação para a sociedade, com o menor custo possível. O contraste com as instituições particulares torna-se inevitável já que o interesse parece estar no maior número possível de alunos para cada professor, sendo inviável manter um professor para ministrar aula para poucos alunos. Aqui temos, portanto, uma relação interessante: enquanto na pública se quer o menor custo, na privada se quer o maior lucro, portanto, o maior número de alunos.

De modo geral, os aspectos aqui trazidos de Silva (2015) nos ajudam a explicitar as contribuições do sujeito que narra para a escrita da história, e o quanto essa fonte é importante na constituição da memória das instituições. A narrativa produzida por meio da História Oral, - que não é um mero texto de um momento de narração de episódios, também não é uma textualização de uma entrevista conduzida somente pelo entrevistador e seu roteiro, mas sim, pelo colaborador, com seu modo de narrar que define o eixo condutor da entrevista - e tomada por nós, com esse olhar de patrimônio educativo, repleta de aproximações e cruzamentos sobre determinado tema de estudo, busca preservar elementos da educação disparados pelas experiências dos colaboradores.

\section{CONSIDERAÇÕES FINAIS}

A História Oral, enquanto metodologia de pesquisa na área da História da Educação Matemática, devido a maturidade alcançada - já que o grupo GHOEM, do qual as autoras deste texto são integrantes, tem produzido várias pesquisas nos últimos anos - tem, concebido uma perspectiva metodológica em movimento, que alarga e diversifica as orientações, fontes, temas, perspectivas, discursos, pontos de vistas; constituindo a convergência com outros campos de conhecimento além da História e da Educação Matemática. 
Esta movimentação metodológica é que propiciou as discussões aqui apresentadas, desejando-se a intensificação dos estudos e ações em defesa, de que as narrativas - constituídas como fontes de pesquisa em trabalhos da História da Educação Matemática -, em nossas pesquisas, possam ser consideradas patrimônio educativo, e por meio da divulgação desse patrimônio educativo, contribuir para a produção do conhecimento científico e para sua projeção social, cultural e acadêmica.

Tal ideia, surge, como podemos ver ao longo do texto, por meio dos componentes teóricos homólogos inclusos na História Oral, uma vez que, por meio dos elementos disparadores, presentes nas narrativas, podemos trazer a cena vários objetos educacionais, que são considerados pelos narradores que vivenciaram certas situações, como heranças, pois, a convergência entre as experiências narradas, mostram-nos que vários colaboradores comungam a intenção de manter preservada uma memória, por meio da narrativa. Assim, utilizam esse meio não somente para falar sobre o tema de estudo do pesquisador, mas para falar sobre outros temas, outras experiências, que julga importante de se preservar. Desfrutam desse momento, como já observado por Martins-Salandim (2012) para fazer reflexões, denúncias, análises de situações vivenciadas, ou ainda para prestar uma homenagem, uma expressão de ressentimentos e também de realizações. Indo além, traz elementos específicos do contexto escolar, como a infraestrutura, a abertura e extinção de cursos, os materiais didáticos, os trabalhos desenvolvidos pelos alunos e pelos professores, documentos institucionais, ementa, etc.

As análises das narrativas dos nossos colaboradores demonstram várias dimensões das instituições de ensino, algumas conhecidas e reconhecidas, outras que só por meio do depoimento dos colaboradores é que são reveladas. Em tal perspectiva destacamos muitos elementos, aqui apresentados das narrativas produzidas em Silva (2015) sobre o espaço e a sua organização, a caracterização dos atores educativos - alunos e professores -, o destaque para a forma que funcionavam os cursos e as formas como os professores trabalhavam. Pode-se ainda destacar que elementos como os materiais educativos, os currículos (formal e informal), a organização das práticas, as normas e regras das instituições de ensino, também são recorrentes nas narrativas, deste mesmo tipo, em nossos trabalhos. Podemos afirmar, que a narrativa, em trabalhos como os nossos, trazem ricos elementos para a história da educação, pois permitem sobressair elementos presentes na vida escolar que por muito tempo permaneceram na penumbra e no silêncio.

Evidentemente, aqui tratamos de refletir pontualmente, sobre narrativas históricas de cursos específicos de formação de professores de Matemática no centro-oeste brasileiro, mas, nossa intenção foi tencionar a legitimidade de reconhecer a narrativa, não somente como meio

Rev. Iberoam. Patrim. Histórico-Educativo, Campinas (SP), v. 5, p. 1-20, e019004, 2019 
para produção historiográfica, mas também, como patrimônio educativo. Dessa forma, a narrativa passa a ser vista para além da memória afetiva da experiência com os cursos, mas particularmente, passa a ser, elemento basilar que permite a reflexão sobre o significado e ressignificado desses cursos de formação de professores.

Concluímos com a ideia de que é possível sim, por meio dos nossos estudos, entender o patrimônio educativo para além do material, no qual se busca transmitir e preservar heranças educacionais, reconhecidas em discursos isolados que apesar de não possuir aparentemente ligação, estão conectados e coexistem, interagem e até se ressignificam.

\section{REFERÊNCIAS}

ALBUQUERQUE JÚNIOR, D. M. História: a arte de inventar o passado. Bauru: EDUSC, 2007.

BENJAMIN, W. O Narrador: considerações sobre a obra de Nikolai Leskov. In: BENJAMIN, W.. Magia e técnica, arte e política: ensaios sobre literatura e história da cultura. São Paulo: Brasiliense, 1994. p. 197-221.

BOLÍVAR, A.; DOMINGO, J.; FERNÁNDEZ, M. La investigación biográfico-narrativa en educación: enfoque y metodologia. Madrid: La Muralla, 2001.

BRUNER, J. A Construção Narrativa da Realidade. Critical Inquiry, 18 (1), p. 1-21, 1991. Tradução Waldemar Ferreira Netto.

CARVALHO, M. L. M. de. Patrimônio, Trabalho e Educação: a história oral significando lugares, professores e estudantes na educação profissional. SEMINÁRIO NEHO VINTE ANOS: HISTÓRIA ORAL, IDENTIDADE E COMPROMISSO, São Paulo, 10 a 12 de novembro de 2011. Anais [...] 2011.

CARVALHO, M. L. M. de.; RIBEIRO, S. L. S. História Oral na Educação: memórias e identidades. São Paulo: Imprensa Oficial do Estado de São Paulo, 2013.

CHERVEL, A. Historia das disciplinas escolares: reflexões sobre um campo de pesquisa. In: Teoria \& Educação, São Paulo, n. 6, p. 177-229, 1990.

FERNANDES, F. S. Biografia do Orvalho: considerações sobre narrativa, vida e pesquisa em Educação Matemática. Bolema, Rio Claro, v. 28, n. 49, p. 896-909, 2014.

GARNICA, A. V. M. Manual de História Oral em Educação Matemática: outros usos, outros abusos. SEMINÁRIO NACIONAL DE HISTÓRIA DA MATEMÁTICA, Guarapuava/ PR, 2007. Anais [...] 2007.

GARNICA, A. V. M. História oral em educação matemática: um panorama sobre pressupostos e exercícios de pesquisa. História Oral, v. 18, n. 2, p. 35-53, jul./dez. 2015. 
GARNICA, A. V. M.; FERNANDES, D. N.; SILVA, H. Entre a amnésia e a vontade de nada esquecer: notas sobre regimes de historicidade e história oral. Bolema, Rio Claro, p. 213-250, 2011.

GOMES, M. L. M. Escrita autobiográfica e história da educação matemática. Bolema: Boletim de Educação Matemática, Rio Claro, SP, v. 26, n. 42, p. 105-138, abr. 2012.

GONZALES, K.G. Formar professores que ensinam Matemática: uma história do movimento das Licenciaturas Parceladas no Mato Grosso do Sul. 2017. 534 f. Tese (Doutorado em Educação para a Ciência) - Faculdade de Ciências, Universidade Estadual Paulista, Bauru/SP.

JULIA, D. A cultura escolar como objeto histórico. Trad. Gizele de Souza. Revista Brasileira da História da Educação, Campinas/SP: Autores Associados, n. 1, p. 8-43, jan./jun. 2001.

LE GOFF, J. A História Nova: A História Nova. In: LE GOFF, J. (Org.). A História Nova. 5. ed. São Paulo: Martins Fontes, 2005. p. 32-89. Tradução de Eduardo Brandão.

LARROSA, J. Notas sobre a experiência e o saber da experiência. Revista Brasileira de Educação, n 19, p. 19-28, jan./abr. 2002.

LARROSA, J.. 20 minutos na fila: sobre experiência, relato e subjetividade em Imre Kertész. Boletim de Educação Matemática, v. 28, n. 49, p. 717-743, ago. 2014.

MARTINS-SALANDIM, M. E. A interiorização dos cursos de Matemática no Estado de São Paulo: um exame da década de 1960. 2012. 374 f. Tese (Doutorado em Educação Matemática) - Instituto de Geociências e Ciências Exatas, Universidade Estadual Paulista, Rio Claro/SP.

MEIHY, J. C. S. B.; HOLANDA, F. História Oral: como fazer, como pensar. São Paulo: Contexto, 2007. 175 p.

MIGUEL, A. O que dizem os estudos já elaborados sobre a emergência da história da educação matemática no Brasil? In: VALENTE, W.R. História da educação matemática no Brasil: problemáticas de pesquisa, fontes, referências teórico-metodológicas e histórias elaboradas. São Paulo: Livraria da Física, 2014. p. 30-46.

MOGARRO, M. J. Património educativo e modelos de cultura escolar na Historia da Educação em Portugal. Cuestiones pedagógicas, 22, p. 67-102, 2013.

NORA, P. Entre memória e história: a problemática dos lugares. Projeto História: revista do Programa de Estudos Pós-Graduados em História e do Departamento de História da Pontifícia Universidade Católica de São Paulo, São Paulo, n. 10, p. 7-28, dez. 1993.

PACHECO, R. D. A. Educação, memória e patrimônio: ações educativas em museu e o ensino de história. Revista Brasileira de História, 30 (60), 2010.

RICOEUR, P. Tempo e narrativa. Campinas (SP): Papirus, 1997. 
SILVA, C. R. M. da. Uma, nove ou dez narrativas sobre as Licenciaturas em Ciências e Matemática em Mato Grosso do Sul. 2015. 368 f. Tese (Doutorado em Educação Matemática) - Instituto de Geociências e Ciências Exatas, Universidade Estadual Paulista, Rio Claro/SP.

SOUZA, L. A. Trilhas na construção de versões históricas sobre um grupo escolar. 2011. 422 f. Tese (Doutorado em Educação Matemática) - Instituto de Geociências e Ciências Exatas, Universidade Estadual Paulista, Rio Claro/SP, 2011.

SOUZA, R. F. de. Preservação do Patrimônio Histórico Escolar no Brasil: notas para um debate. Revista Linhas, Florianópolis, v. 14, n. 26, p. 199-221, jan./jun. 2013.

VIANNA, C. R. Sinfonia n. ${ }^{\circ} 5$ em Dó menor. Zetetiké: Revista de Educação Matemática, v. 23, n. 43, p. 45-57, 2016.

VIÑAO, A. Memoria, patrimonio y educación. História da Educação, v. 15, n. 33, p. 31-62, 2011.

VIDAL, D. G. No interior da sala de aula: ensaio sobre cultura e prática escolares. Currículo sem fronteiras, 9, n. 1, p. 25-41, 2009.

Recebido em: 31 de agosto de 2018

Aceito em: 22 de dezembro de 2018 